\title{
Prevalence of Canine Hemotrophic Mycoplasma in Kannur District of Kerala, India
}

\author{
P. Preena ${ }^{1 *}$, Divya Mohan ${ }^{2}$, Sherin B. Sarangom ${ }^{1}$, Seeja Sundaran ${ }^{1}$, \\ Keerthana Santhosh ${ }^{1}$, K.V. Ramesh Kumar ${ }^{3}$ and C.P. Prasad ${ }^{1}$ \\ ${ }^{1}$ District Veterinary Centre, Kannur \\ ${ }^{2}$ Veterinary Dispensary, Cheriyamundam, Malappuram \\ ${ }^{3}$ Regional Artificial Insemination Centre, Kannur \\ *Corresponding author
}

\begin{tabular}{|l|}
\hline Ke y w o r d s \\
Canine \\
Hemotrophic \\
Mycoplasma, \\
haemoplasma \\
\hline Article Info \\
\hline $\begin{array}{l}\text { Accepted: } \\
\text { 22 June } 2020 \\
\text { Available Online: } \\
\text { 10 July } 2020\end{array}$ \\
\hline
\end{tabular}

\section{A B S T R A C T}

Hemotropic mycoplasmas in dogs, such as Mycoplasma haemocanis, have been described worldwide. Little data are available on the prevalence of haemoplasma infections in dogs of India. The objective of the study was to investigate the prevalence, hematological changes and risk factors of canine haemoplasmosis in Kannur district of Kerala where tick vectors are highly prevalent. To address this, dogs $(\mathrm{N}=1,235)$ with tick infestation were studied during the period from November 2019 to June 2020. Microscopic blood smear examination was used to establish the prevalence and primary screening of canine haemoplasmosis. Thirty four dogs $(2.75 \%)$ were positive for Mycoplasma organisms, of this 25 animals (74\%) were found to be co-infected by Babesia gibsoni. Hematological analysis revealed that co-infection of dogs with Mycoplasma spp. and B. gibsoni had exacerbated the anemic status of the animal. It was also found that the host risk factors like age, breed and gender of dogs had insignificance in occurrence of Mycoplasma infection. The results from the present study reinforced the notion that canine haemotrophic Mycoplasma as a potential pathogen causing anemia in susceptible animals. Besides, co-infection with other blood parasites would complicate the anemic crisis and complicate diagnosis. The study further demands molecular investigation into the situation to probe the exact prevalence and epidemiology of the disease for exploiting effective control measures.

\section{Introduction}

Canine tick borne diseases (TBD) in Indian subcontinent causing wide range of clinical effects were Hepatozooncanis, Ehrlichiacanis, Mycoplasma haemocanis,
Anaplasmaplatys, Babesiavogeli and Babesia gibsoni (Abd Rani et al., 2011). Canine haemotropic mycoplasmosis or haemoplasmosis is an emerging epierythrocytic parasitic infection with a relative paucity of studies in India 
(Dhanalakshmi et al., 2017; Tresamol and Ameldev, 2018). Haemoplasmas are small, uncultivable, cell wall less bacteria causing chronic, asymptomatic conditions to severe hemolytic anemia in immunocompromised or splenectomised animals (Messick, 2003). Previous studies suggests that additional factors like immunosuppression or coinfections like mange, blood parasites etc. may be necessary to precipitate the conditions like fever, anorexia, anaemia and thrombocytopenia in hemoplasma-infected animals (Novacco et al., 2010; Tresamol and Ameldev, 2018). Three different hemoplasma species,formerly named as Haemobartonella, have been recognized in dogs namely, Mycoplasma haemocanis, Candidatus Mycoplasma haemominutum and Candidatus M. haematoparvum (Zheng et al., 2017). Natural means of transmission of canine hemoplasmas have not been largely explored; ectoparasites like mites, fleas and ticks were proposed to be the possible vectors. It was also suggested that transmission can occur during blood tranfusions, aggressive interactions, contaminated fomites and transplacentally. The brown dog tick, Rhipicephalus sanguineus has been considered as main vector for the transmission of $M$. haemocanis among dogs (Ravagnan et al., 2017; Messick, 2003).

Microscopic examination of the stained peripheral blood smears revealing single, pairs or chain of organisms on the surface of erythrocytes were used for preliminary diagnosis of the condition. The clinical signs of canine tick borne diseases are often diffuse and overlapping, leading to a substantial diagnostic challenge to the veterinarians. Moreover, co-infections with two or more pathogens may enhance this problem further (Anderson et al., 2017). The current protocol for treatment of haemotrophic mycoplasma infection includes the use of tetracycline antibiotics like oxytetracycline and doxycycline for three weeks (Chalker, 2005). Little data are available on the prevalence of hemoplasma infections in dogs of India. Hence, the present study was designed to investigate the occurrence and the potential host risk factors of canine haemotropic mycoplasmosis in Kannur district of Kerala using conventional diagnostic techniques.

\section{Materials and Methods}

\section{Study population}

The present study was conducted in 1,235 dogs from different parts of Kannur district enrolled in outpatient ward, District Veterinary Centre, Kannur (Kerala) during the period from November 2019 to June 2020. Sampling was performed only from dogs with history of tick infestation with no restrictions regarding age, gender and breed. Clinical health status like healthy or sick, based on the dog's history and clinical examination, and epidemiological information like age, sex, breed and demographic area of all animals were also obtained. The study area is Kannur district which is a coastal city in the northern part of south Indian state of Kerala. It is located on the western coast of the country which lies in the latitude of $11^{\circ} 52^{\prime} 28.1172^{\prime \prime}$ $\mathrm{N}$ and longitude of $75^{\circ} 22^{\prime} 13.3284^{\prime \prime} \mathrm{E}$ with an elevation of 20 meters height. The tropical bioenvironment in Kannur district remarkably facilitate the tick infestation and their by transmission of various tick borne pathogens as observed by Preena et al., (2019).

\section{Light microscopic examination}

Peripheral blood smears were prepared from ear margins, air-dried and fixed in $100 \%$ ethanol and evaluated microscopically using Giemsa method, for the presence of piroplasms (Babesia spp.), inclusion bodies (Anaplasma spp. or Ehrlichia spp.), or small basophilic structures on the periphery of 
erythrocytes as indication of hemotropic Mycoplasma infections under oil immersion (100X).

\section{Haematological examination}

Around $2 \mathrm{ml}$ of blood was collected from either the cephalic vein / recurrent tarsal vein in EDTA vials. Complete blood count analysis was performed on an automatic haematology analyzer (Exigo EOS, Sweden).

\section{Statistical analysis}

The data obtained were represented as mean \pm standard deviation. All haematological parameters were evaluated statistically using one-way ANOVA with Duncan's multiple range test. The association of the hemoplasmosis and various risk factors were tested for statistical significance using Chisquare test. The statistical Package for Social Sciences (SPSS Version 20.0.0) was used in the study. Variables with $p<0.05$ were considered as statistically "significant".

\section{Results and Discussion}

The first documented case of canine mycoplasmosis was in 1934 (Shoetensack, 1934). Mycoplasma infections were known to cause anaemia in certain cases by deformation and autoantigen exposure of erythrocytes leading to clearance of these infected RBCs by host immune response through spleen. Deformation of erythrocytes occurs during penetration of hemoplasma fibrils into its membrane for getting nutrition causing the increased permeability and fragility of the membrane leading to haemolytic anaemia (Yang et al., 2007). Canine haemotrophic Mycoplasma are cosmopolitan in occurrence, however in India, scare reports are available. Hence, the occurrence, distribution and frequency of Mycoplasma spp. in 1235 dogs were determined in this study. The dogs with history of tick infestation were selected in the study as it was previously stated by Abd Rani et al., (2011) that dogs infected with ticks were likely to positive for at least one or more canine TBD pathogen than dogs without tick infestation. Spherical or ring-shaped microorganisms were detected at the periphery of erythrocytes by microscopy in 34 $(2.75 \%)$ dogs out of a total of 2,345 examined (Figure 2). Similarly, presence of small coccoid organisms in the periphery of RBCs in a severe anemic dog had been described by Tresamol and Ameldev (2018). Among the Mycoplasma positive animals, 25 animals (74\%) were found to be co-infected by Babesia gibsoni. A similar study has also been reported by Anderson et al., (2017) wherein a $\operatorname{dog}$ with $B$. gibsoni infection also harboured M. haemocanis.

Haematological attributes of Mycoplasma infected dogs, B. gibsoni co-infected dogs and healthy dogs are described in Table 1 . There was significant difference in $\mathrm{Hb}$ and $\mathrm{RBC}$ values in Mycoplasma infected dogs and $B$. gibsoni co-infected dogs. Severity in anemia may be due to fact that co-infection in dogs with more than one pathogen may exacerbate clinical manifestations leading to unpredictable incubation period, clinical outcome and prognosis (Otranto et al., 2009). Haematological analysis revealed thrombocytopenia, decrease in neutrophil count, increase in lymphocyte count and monocyte count in infected animals when compared to the healthy dog population as similarly described by Preena et al., (2019). In the figure 1, polychromatophilic RBCs were portrayed which are bluish coloured immature anucleated erythrocytes indicating regenerative anaemia due to the hemolytic effects of the pathogen. Distribution of Mycoplasma spp. among the dog population studied with relation to various risk factors has been depicted in Table 2. In the study, it was found that the age, breed and gender of 
dogs has insignificance in occurrence of Mycoplasma infection in concordance with the previous studies of Roura et al., (2010); Ravagnan et al., (2017) and Aquino et al., (2014), who also found no association between hemoplasma prevalence and other potential risk factors like clinical status, anaemia, ectoparasites, prophylaxis etc.
However, it was found that young dogs were more frequently infected to hemoplasma which may be due to higher exposure rate to tick vectors. Moreover, it was postulated that the living conditions and climate were casually linked with the increased risk of hemoplasma infection rather than the breed of the dogs (Novacco et al., 2010).

Figure.1 Geographical location of Kannur district of Kerala where the study was conducted

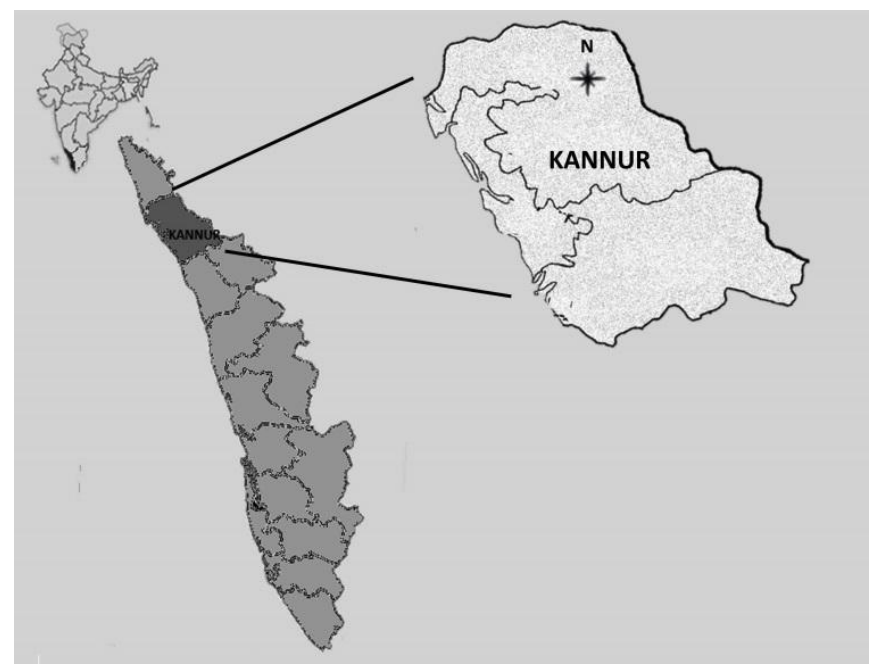

Fig.2 Photomicrograph of Geimsa stained blood smear from a dog in which numerous small black dot-like Mycoplasma infected erythrocyte (red arrowhead) co-infected with signet ring shaped B. gibsoni (black small arrow). Two polychromatophils (P) could also be observed which are immature erythrocytes indicating regenerative anemia

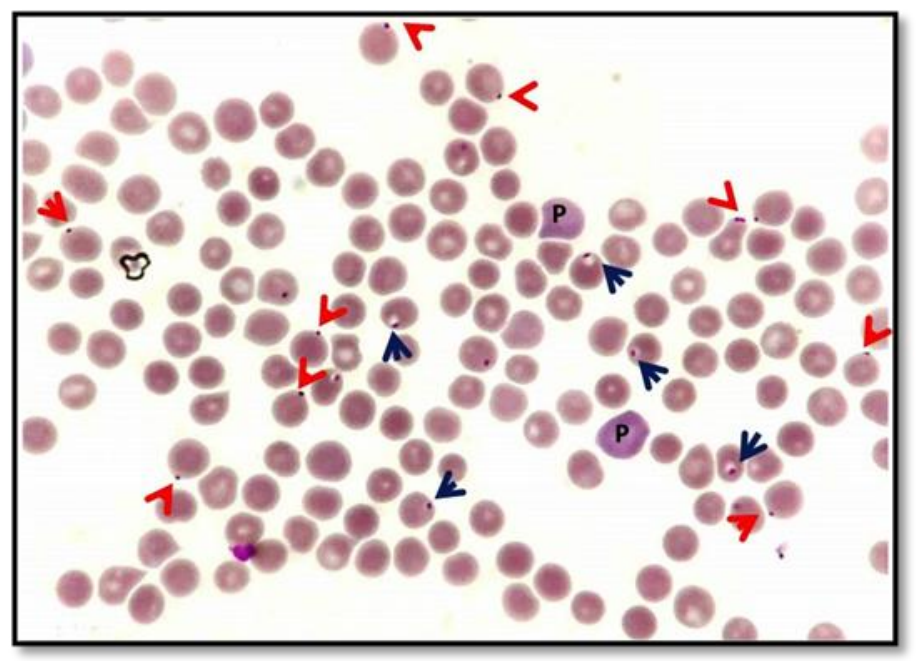


Table.1 Haematological values of affected and healthy dogs (Mean \pm Standard deviation)

\begin{tabular}{|c|c|c|c|}
\hline Categories & $\begin{array}{c}\text { Mycoplasma } \\
\text { positive animal }\end{array}$ & $\begin{array}{c}\text { Co-infected } \\
\text { animals }\end{array}$ & Healthy dogs \\
\hline $\mathbf{H b}(\mathbf{g} / \mathbf{d l})$ & $9.7 \pm 2.13^{\mathrm{a}}$ & $7.47 \pm 2.61^{\mathrm{b}}$ & $14.49 \pm 1.63^{\mathrm{c}}$ \\
\hline $\mathbf{R B C}\left(\times \mathbf{1 0}^{\mathbf{6}} / \boldsymbol{\mu l}\right)$ & $4.27 \pm 1.12^{\mathrm{a}}$ & $2.97 \pm 1.14^{\mathrm{b}}$ & $6.39 \pm 0.63^{\mathrm{c}}$ \\
\hline Platelet $\left(\times \mathbf{1 0}^{\mathbf{3}} / \boldsymbol{\mu l}\right)$ & $1.22 \pm 1.30^{\mathrm{a}}$ & $0.64 \pm 0.50^{\mathrm{a}}$ & $2.93 \pm 0.63^{\mathrm{b}}$ \\
\hline $\mathbf{T C}\left(\times \mathbf{1 0}^{\mathbf{3}} / \boldsymbol{\mu l}\right)$ & $9.69 \pm 2.89^{\mathrm{ac}}$ & $13.39 \pm 4.56^{\mathrm{b}}$ & $10.99 \pm 2.87^{\mathrm{bc}}$ \\
\hline $\mathbf{N P}(\boldsymbol{\%})$ & $55.89 \pm 9.3^{\mathrm{a}}$ & $56.15 \pm 10.13^{\mathrm{a}}$ & $73.57 \pm 5.47^{\mathrm{b}}$ \\
\hline $\mathbf{L C}(\boldsymbol{\%})$ & $32.44 \pm 8.76^{\mathrm{a}}$ & $32.35 \pm 9.92^{\mathrm{a}}$ & $17.93 \pm 3.83^{\mathrm{b}}$ \\
\hline $\mathbf{M C}(\%)$ & $11.67 \pm 2.12^{\mathrm{a}}$ & $11.5 \pm 3.19^{\mathrm{a}}$ & $8.5 \pm 2.79^{\mathrm{b}}$ \\
\hline
\end{tabular}

a,b,c: Means \pm SD with different letter as super scripts within a row differ significantly

Table.2 Distribution of Mycoplasma spp. among dog population studied

\begin{tabular}{|l|c|}
\hline \multicolumn{1}{|c|}{ Variables } & $\begin{array}{c}\text { No. (\%) positive for } \\
\text { Mycoplasma spp. }\end{array}$ \\
\hline Gender: & \\
\hline Male & $20(58.82)$ \\
\hline Female & $14(41.18)$ \\
\hline Age group: & $16(47.06)$ \\
\hline Young (<1 year) & $18(52.94)$ \\
\hline Adult (> 1 year) & $3(8.82)$ \\
\hline Breeds: & $1(2.94)$ \\
\hline Dalmatian & $3(8.82)$ \\
\hline Dachshund & $2(5.88)$ \\
\hline Doberman & $3(8.82)$ \\
\hline Golden retriever & $7(20.59)$ \\
\hline German Shepherd & $3(8.82)$ \\
\hline Labrador & $4(11.76)$ \\
\hline Pug & $5(14.71)$ \\
\hline Rottweiler & $3(8.82)$ \\
\hline Spitz & \\
\hline Other & $9(26)$ \\
\hline Infection: & $25(74)$ \\
\hline Mycoplasma infection & \\
\hline Mycoplasma \&B.gibsoni & \\
\hline co-infection
\end{tabular}

In the present study, conventional methods were utilized to assess the prevalence of canine hemotrophic mycoplasmosis. In addition, the hemoplasma infected dogs in the present study did not exhibit clinical signs and hematological variations clearly attributing it to canine hemoplasma infection and differentiating it from commonly prevalent 
babesiosis in the study area. Only B. gibsoni was found to be the infection concurrently seen with the Mycoplasma which was found to aggrevate the clinical condition of the affected dogs complicating the diagnosis. This also warrants the requirement of an elaborated study on the prevalence or effects of co-infection of other prevalent infections like Babesiacanis, Ehrilichiacanis, mange and dirofilariasis which are highly prevalent in the area. Bacterial infection with Mycoplasma spp. occurred in a substantial number of dogs studied indicating a rather high rate of transmission of the pathogen in the dog population in Kannur.

There are some limitations in the present study, which still haveto be mentioned. The specificity of blood smear examination may be poor due to subclinical or chronic conditions. In addition, false positive results may be obtained in case of inappropriate staining or fixation methods and intraerythrocytic inclusions like Howell-Jolly bodies (Ameldev and Tresamol, 2018). Hence, advanced molecular methods are essential to find the real prevalence of the condition and the factors associated with concurrent infection. Genomic sequencing of haemoplasma organism is essential for identifying the transmission, virulence factors, protein antigens and genetic variability for better prevention control of the condition.

Vector-borne diseases are one of the most complex of all infectious diseases to diagnose, mitigate, control and prevent. In this work, we presented the high prevalence of Mycoplasma infection in dog from Kannur district suggesting a potential role of causing anemia in susceptible animals. Henceforth, this study warrants the need for investigation of epidemiological patterns, vector distribution and economic impact of the condition in canine populations of the country.

\section{Conflict of interest}

None of the authors of this article has a financial or personal relationship with other people or organizations that could inappropriately influence or bias the content of the paper.

\section{Acknowledgement}

The authors acknowledge the technical and financial support provided by the Director, Dept. of Animal Husbandry, Kerala for the study.

\section{References}

Abd Rani, P.A.M., Irwin, P.J., Coleman, G.T., Gatne, M. and Traub, R.J. 2011.A survey of canine tick-borne diseases in India. Parasit. Vectors. 4(1):141.

Ameldev, P. and Tresamol, P.V. 2018. Hemotropic Mycoplasmosis-Emerging Cause of Infectious Anaemia in Dogs and Cats. Int. J. Curr. Microbiol. App. Sci, 7(1):1308-1311.

Andersson, M.O., Tolf, C., Tamba, P., Stefanache, M., Waldenström, J., Dobler, G. and Chițimia-Dobler, L. 2017.Canine tick-borne diseases in pet dogs from Romania. Parasit.Vectors. 10(1):1-6.

Aquino, L.C., Hicks, C.A., Scalon, M.C., Lima, M.G.D.M., Lemos, M.D.S., Paludo, G.R., Helps, C.R. and Tasker, S. 2014. Prevalence and phylogenetic analysis of haemoplasmas from cats infected with multiple species. $J$. Microbiol. Methods. 107:189-196.

Dhanalakshmi, H., Veena, M. and Kavitha. 2017. Diagnosis and Management of Haemotropic Mycoplasmosis in Dogs. IntasPolivet, 18(1):192-193.

Messick, J.B. 2003. New perspectives about Hemotrophic mycoplasma (formerly, Haemobartonella and Eperythrozoon 
species) infections in dogs and cats. Vet. Clin.North Am. Small Anim. Pract. 33(6): 1453-1465.

Novacco, M., Meli, M.L., Gentilini, F., Marsilio, F., Ceci, C., Pennisi, M.G., Lombardo, G., Lloret, A., Santos, L., Carrapiço, T. and Willi, B. 2010.Prevalence and geographical distribution of canine hemotropic mycoplasma infections in Mediterranean countries and analysis of risk factors for infection. Vet. Microbial. 142(3-4): 276-284.

Otranto, D., Dantas-Torres, F. and Breitschwerdt, E.B. 2009. Managing canine vector-borne diseases of zoonotic concern: part two. Trends Parasitol.25(5): 228-235.

Preena, P., Divya Mohan and C.P. Prasad. 2019. Predominant prevalence of Babesia gibsoni infection and its haematological Alterations in Canine Populationsof Kannur district, Kerala. Journal of Indian Veterinary Association, Kerala (JIVA). 19(3): 2331.

Ravagnan, S., Carli, E., Piseddu, E., Da Rold, G., Porcellato, E., Zanardello, C., Carminato, A., Vascellari, M. and Capelli, G. 2017. Prevalence and molecular characterization of canine and feline hemotropic mycoplasmas (hemoplasmas) in northern Italy. Parasit.Vectors. 10(1):132.

Roura, X., Peters, I.R., Altet, L., Tabar, M.D., Barker, E.N., Planellas, M., Helps, C.R.,
Francino, O., Shaw, S.E. and Tasker, S. 2010. Prevalence of hemotropic mycoplasmas in healthy and unhealthy cats and dogs in Spain. J. Vet. Diagn. Invest. 22(2): 270-274.

Shoetensack, H.M. 1934. Pure cultivation of filterable virus isolated from canine distemper. The Kitasato Archives of Experimental Medicine, 11:.227-290.

Soares, R.L., Echeverria, J.T., Pazzuti, G., Cleveland, H.P.K., Babo-Terra, V.J., Friozi, E. and Ramos, C.A.D.N. 2016. Occurrence of Mycoplasma haemocanis in dogs infested by ticks in Campo Grande, MatoGrossodoSul, Brazil. Rev. Bras.Parasitol. Vet. 25(3): 360-363.

Trapp, S.M., Messick, J.B., Vidotto, O., Jojima, F.S. and de Morais, H.S.A. 2006. Babesia gibsoni genotype Asia in dogs from Brazil. Vet.Parasitol.141(12): 177-180.

Tresamol P. V and Ameldev, P. 2018. Molecular confirmation and therapeutic management of haemotropic mycoplasmosis in a dog, a case study. Int. J. Curr. Adv. Res. 7:13953-13955.

Yang, Z., Yuan, C., Yu, F. and Hua, X. 2007. Haemotrophic mycoplasma: review of aetiology and prevalence. Rev. Med.Microbiol. 18(1):1-3.

Zheng, W.Q., Chen, H.Y., Liu, M.M., Adjou Moumouni, P.F., Efstratiou, A., Liu, Z.B. and Xuan, X.N. 2017.First evidence of Mycoplasma haemocanis in China. Trop Biomed. 34: 983-990.

\section{How to cite this article:}

Preena, P., Divya Mohan, Sherin B. Sarangom, Seeja Sundaran, Keerthana Santhosh, K.V. Ramesh Kumar and Prasad, C.P. 2020. Prevalence of Canine Hemotrophic Mycoplasma in Kannur District of Kerala, India. Int.J.Curr.Microbiol.App.Sci. 9(07): 3668-3674. doi: https://doi.org/10.20546/ijcmas.2020.907.430 